\title{
CARACTERIZAÇÃO DA BACIA DO ARROIO CASTELHANO: DISPONIBILIDADE HÍDRICA, RISCOS DE INUNDAÇÕES E INTERAÇÃO COM A CIDADE DE VENÂNCIO AIRES/RS
}

\author{
Fernando Alves Cantini Cardozo ${ }^{1,2 *}$ Carlos Otávio Petter ${ }^{1}$ \\ $1^{1}$ Departamento de Engenharia de Minas, Universidade Federal do Rio Grande do Sul, 9085000, Porto Alegre, Brasil. \\ ${ }^{2}$ Secretaria de Meio Ambiente, Município de Venâncio Aires, 95800000, Venâncio Aires, Brasil.
}

*E-mail: fernando.cantini3@gmail.com

Recebido em: 13/01/2020 Aceito em: 07/07/2020

\section{RESUMO}

Este trabalho visa caracterizar a bacia do Arroio Castelhano e sua relação com o município de Venâncio Aires. Apresenta-se como a natureza geomorfológica dessa bacia e o uso do solo no meio rural e urbano influenciam tanto na qualidade da água desse recurso hídrico quanto nas suas vazões e nos episódios de inundação. Analisando-se índices morfológicos e geomorfologia, observa-se que a bacia do arroio apresenta tendência a inundações no seu trecho médio. Identifica-se, de acordo com a geomorfologia e o uso do solo, que a área com maior possibilidade de intervenção quanto aos episódios de inundação está situada na zona urbana e na zona rural próxima a esta, ambas de baixa declividade

Palavras-chave: Arroio Castelhano. Bacia Hidrográfica. Município de Venâncio Aires.

\section{Introdução}

O Arroio Castelhano apresenta uma estreita relação com a cidade de Venâncio Aires/RS, estando sua bacia situada em maior parte nessa cidade. Trata-se do principal recurso hídrico da região, uma vez que atende às necessidades de água da indústria, da agricultura e do consumo humano local. Considerando-se a presença relevante de fluoreto nas águas subterrâneas da região, a qual é causadora de diversas situações de fluorose [1], limitando, assim, o uso da água subterrânea, constata-se uma maior importância das águas superficiais da bacia na segurança hídrica da região.

Tal como diversas outras populações, o município de Venâncio Aires ocupou as áreas planas próximas ao principal recurso hídrico da região, o Arroio Castelhano. Dadas as características geográficas, esse recurso apresenta o padrão de saída de seu leito normal para sua várzea e, consequentemente, em períodos de alta e intensa pluviosidade, atinge áreas habitadas, gerando prejuízos à população. Collischonn [2] afirma que, embora eventos de inundação sejam perigos de ordem natural, são potencializados por fatores sociais, tais como urbanização, interferências nos recursos hídricos, uso e ocupação do solo.

Devido aos episódios recorrentes de inundações que afetam a população local, ocorrências históricas de grande abrangência no município de Venâncio Aires nos anos de 1984 e 2003 relatados por Collischonn [2], e à importância dos recursos hídricos dessa bacia para a região, este trabalho visa contribuir para o entendimento da bacia do Arroio Castelhano, incluindo a relação de suas características físicas e de ações antrópicas nos riscos associados, principalmente as ocorrências de inundações.

\section{2 Área de Estudo}

O município de Venâncio Aires caracteriza-se como de pequeno porte em termos nacionais, contabilizando menos de 100 mil habitantes (Figura 1). Entretanto, considerando-se a realidade do estado do Rio Grande do Sul, encontra-se em um patamar de destaque em termos estaduais e regionais (localizado nos Vales do Taquari e Rio Pardo), estando em uma posição logisticamente privilegiada, próximo à capital, Porto Alegre, e às duas maiores cidades da região, Santa Cruz do Sul e Lajeado. Tal localização, somada à disponibilidade de capital humano e à aptidão agrícola, entre outras características, conferem um IDHM de 0,712 a Venâncio Aires, um dos melhores do Rio Grande do Sul [3]. Outra característica que merece destaque é a distribuição da população da cidade, sendo que em torno de $37 \%$ [3] da população encontra-se no meio rural, em pequenas propriedades, fato que a torna uma das cidades com maior número de pequenas propriedades rurais, com predomínio de propriedades inferiores a um módulo fiscal 
Com relação ao uso de solo no município de Venâncio Aires, um fato a ser destacado é a retomada de vegetação nativa (Mata Atlântica) sobre áreas anteriormente dedicadas à atividade agrossilvipastoril. Oliveira [4] e Collischonn [2] destacam em seus estudos essa particularidade quanto ao uso do solo na zona rural onde, há décadas, antigas áreas cultivadas vêm sendo abandonadas, permitindo a retomada da vegetação nativa. A partir do trabalho de Oliveira [4], observa-se que a maior porção de áreas retomadas pela vegetação nativa (regeneração da Mata Atlântica) localiza-se na região da escarpa da Formação Serra Geral, caracterizada pela declividade e mudança relativamente abrupta do relevo. Entende-se que a dificuldade do manejo agrícola em tais regiões, somada à evolução urbana e industrial, vem tornando mais interessante a migração de atividades e o abandono das propriedades rurais em condições logística e geomorfologicamente desfavoráveis.

A regeneração da vegetação, principalmente nas escarpas, em relação à hidrografia da bacia do Arroio Castelhano, torna-se um ponto de grande destaque e atípico em termos de bacias hidrográficas, uma vez que se deu de maneira “espontânea". Oliveira [4] estimou em 71\% o incremento de vegetação em um período de 28 anos, considerando-se todo o município de Venâncio Aires, destacando-se expressiva porção em área correspondente à Bacia do Arroio Castelhano. Em termos de gestão de recursos hídricos, o acréscimo de vegetação representa uma situação ideal, visto que colabora para a regularização da oferta hídrica, para uma melhora da qualidade da água dos recursos e, em termos de riscos, para um aumento do tempo de concentração (relacionado à ocorrência de inundações). Tucci [5, 6] afirma que áreas vegetadas, em comparação a áreas não vegetadas, apresentam maior infiltração de águas pluviais e, consequentemente, menor escoamento superficial e maior escoamento subsuperficial (ou subterrâneo). Também destaca que uma das principais medidas de controle de vazões, enchentes e inundações é a manutenção de áreas vegetadas.

Outro aspecto destacável, seja da questão de diminuição de escoamentos superficiais, seja da diminuição de processos erosivos, é o carregamento de sedimentos para os recursos hídricos. Maciel e Nummer [7] explicam como o carregamento de sólidos aos recursos hídricos é ambientalmente impactante, sendo responsável por processos de assoreamento e alteração quali-quantitativa de cursos hídricos, acrescentando inclusive que a manutenção inadequada de vias não pavimentadas (maior parte da extensa malha viária de Venâncio Aires e dos municípios brasileiros) é responsável pelo carregamento de consideráveis volumes de sedimentos aos cursos hídricos. Como há um alto volume de sedimentos sendo carreados, observa-se maior ocorrência de extravasamentos de leitos e geração de processos de meandramentos.

\subsection{Estudos Anteriores}

Embora a Bacia do Arroio Castelhano tenha grande importância para a cidade de Venâncio Aires e demais cidades abrangidas, poucos estudos foram realizados sobre esse assunto quanto à área localizada em meio rural. Mesmo para o município de Venâncio Aires como um todo, incluindo-se abordagens de planejamento urbano, verificam-se poucos trabalhos de divulgação científica. Dentre os estudos disponíveis, sobressai a tese de doutorado de Erika Collischonn [2], na qual a autora aborda de forma aprofundada a relação de Venâncio Aires com o Arroio Castelhano e as históricas inundações, aprofundando sua pesquisa na interação do meio físico com a dinâmica social. A Tabela 1 apresenta os estudos de maior relevância sobre o Arroio Castelhano e a cidade de Venâncio Aires, considerandose seu meio físico. 

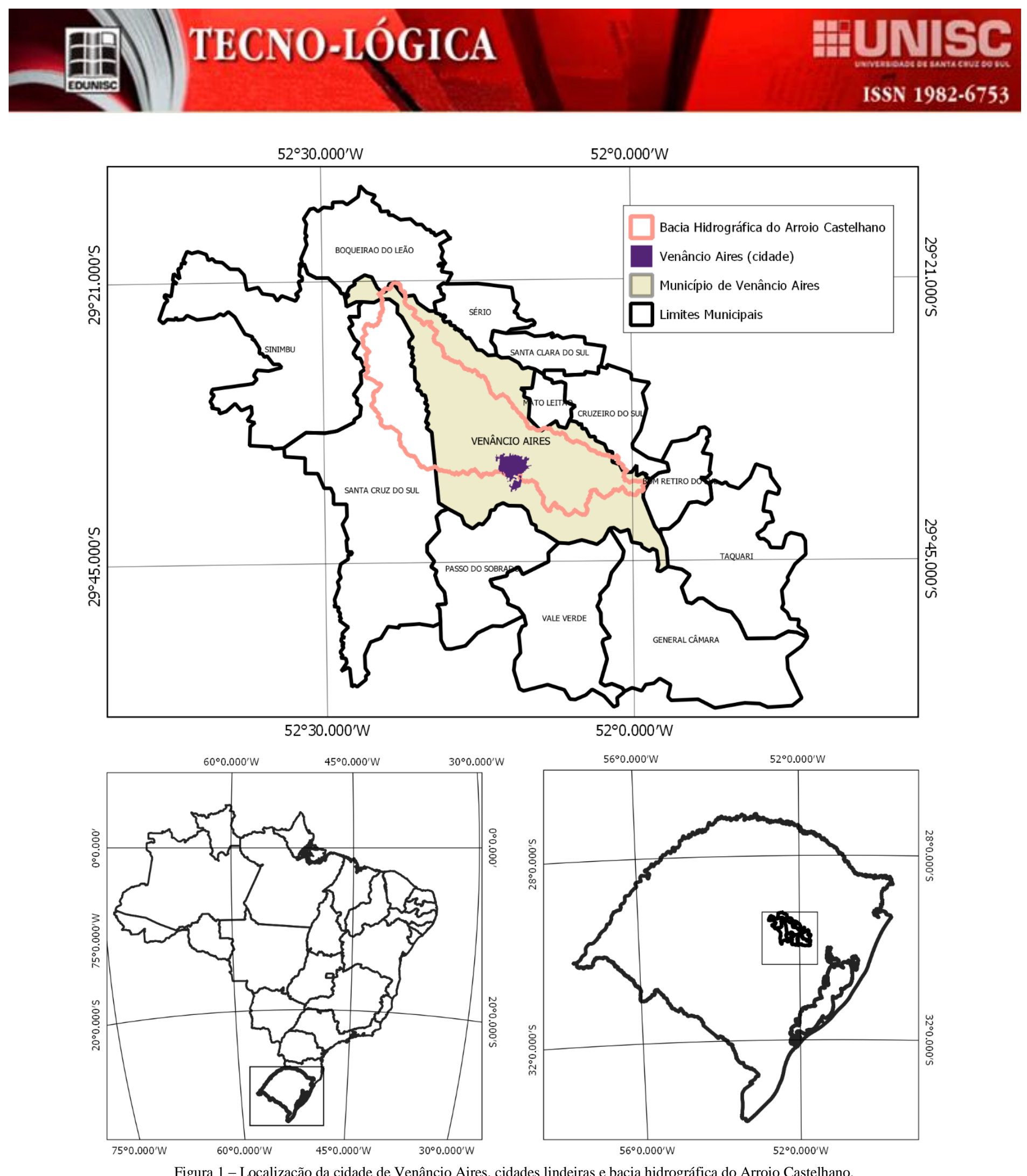

Figura 1 - Localização da cidade de Venâncio Aires, cidades lindeiras e bacia hidrográfica do Arroio Castelhano. 
Tabela 1 - Estudos sobre a Bacia do Arroio Castelhano e Meio Físico de Venâncio Aires

\begin{tabular}{|c|c|c|c|}
\hline Título do Trabalho & Ano & Autores & Natureza do Trabalho \\
\hline $\begin{array}{l}\text { O Flúor nas Águas Subterrâneas da Formação Santa Maria, na Região de } \\
\text { Santa Cruz do Sul e Venâncio Aires }\end{array}$ & 2006 & Marimon [1] & Tese de Doutorado \\
\hline $\begin{array}{l}\text { Inundações em Venâncio Aires/RS: Interações entre as dinâmicas natural e } \\
\text { social na formação de riscos socioambientais urbanos. }\end{array}$ & 2009 & Collischonn [2] & Tese de Doutorado \\
\hline $\begin{array}{l}\text { A Ocupação do Solo em Área Preservação Permanente: O Avanço Sobre a } \\
\text { Planície de Inundação do Arroio Castelhano na Área Urbana de Venâncio } \\
\text { Aires, RS. }\end{array}$ & 2011 & Weschenfelder e Arend [8] & $\begin{array}{l}\text { Artigo publicado em } \\
\text { Anais de Evento }\end{array}$ \\
\hline Planejamento e cidades: plano diretor em Venâncio Aires/RS & 2013 & Lücke [9] & $\begin{array}{l}\text { Dissertação de } \\
\text { Mestrado }\end{array}$ \\
\hline $\begin{array}{l}\text { Response of epilithic diatom communities to downstream nutrient increases } \\
\text { in Castelhano Stream, Venâncio Aires City, RS, Brazil. }\end{array}$ & 2013 & Böhm et al. [10] & $\begin{array}{l}\text { Artigo publicado em } \\
\text { Periódico } \\
\end{array}$ \\
\hline Estatuto da cidade e Plano Diretor em Venâncio Aires/RS. & 2014 & Machado e Lücke [11] & $\begin{array}{l}\text { Artigo publicado em } \\
\text { Periódico } \\
\end{array}$ \\
\hline $\begin{array}{l}\text { Modelagem dinâmica espacial das classes de uso e cobertura da terra de } \\
\text { Venâncio Aires/RS. }\end{array}$ & 2015 & Oliveira [4] & Monografia \\
\hline $\begin{array}{l}\text { Espacialização mensal e anual da chuva nos municípios de Santa Cruz do Sul, } \\
\text { Venâncio Aires, Vera Cruz e Passo do Sobrado no Rio Grande do Sul. }\end{array}$ & 2017 & Marcuzzo [12] & $\begin{array}{l}\text { Artigo publicado em } \\
\text { Anais de Evento }\end{array}$ \\
\hline
\end{tabular}

\subsection{Bacia do Arroio Castelhano e Inundação Urbana}

O Arroio Castelhano apresenta largura média, em seu leito regular, superior a 10 metros, percorrendo a zona rural de Venâncio Aires, com origem no extremo norte do município, passando pela cidade de Santa Cruz do Sul e terminando por desaguar no Rio Taquari, na localidade de Vila Mariante. A Bacia Hidrográfica do Arroio abrange uma área total de $578 \mathrm{~km}^{2}$, compreendendo aproximadamente $54 \%$ da área de Venâncio Aires e $77 \%$ da zona urbana (considerando-se a zona edificada). Em torno de $72 \%$ da área da Bacia localiza-se no município de Venâncio Aires, situando-se a área restante em Santa Cruz do Sul.

A Bacia do Arroio Castelhano é uma das sub-bacias da Bacia do Rio Taquari, um dos principais recursos hídricos do Rio Grande do Sul. Diversos outros Arroios e drenagens de primeira e segunda ordem, principalmente, somados a drenagens de terceira e quarta ordem, compõem a Bacia do Castelhano, fazendo deste arroio uma drenagem de quinta ordem. Destaca-se a contribuição do Arroio Grande (Figura 2), o qual deságua no Arroio Castelhano pouco antes do início da zona urbana.
Considerando um exutório (ponto de saída da drenagem) logo após a zona urbana e, para uma subdivisão da bacia, vemos que tal bacia intermediária contribui com todo o volume de água que chega até este ponto; a qual abrange uma área de aproximadamente $434 \mathrm{~km}^{2}$. Sendo $75 \%$ de toda a bacia do Arroio Castelhano. Assim, temos que três quartos de todo o escoamento, considerada contribuição em função da área, da Bacia do Castelhano passará pelo trecho próximo a zona urbana do Município.

Sobre a qualidade da água do Arroio Castelhano, está mensurada com frequência no ponto de captação para tratamento d'água (coordenada: 29³5'32.91"S, 52¹1'23.22"O. - Sirgas 2000). Observa-se que esse ponto fica a jusante de considerável porção de contribuição da drenagem pluvial, alimentada com efluentes domésticos e industriais.

A zona urbana da cidade está posicionada na bacia intermediária, zona de transição da alta declividade da cabeceira da bacia para declividades brandas. A bacia intermediária normalmente exerce importante papel na ocorrência de inundações, visto que sua baixa declividade gera menores velocidades de escoamento [5]. 

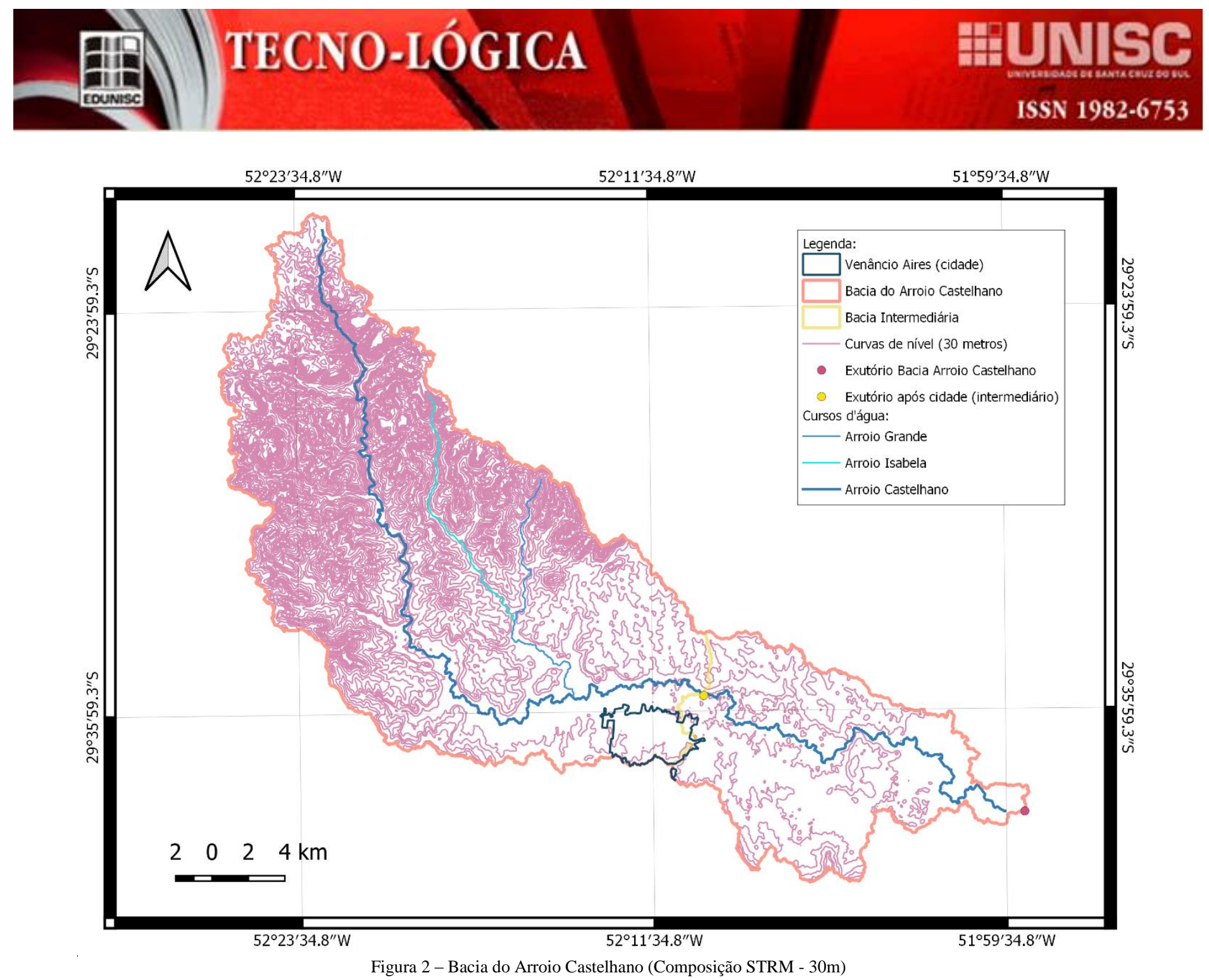

\section{Caracterização da Bacia}

Para caracterização da bacia do Arroio Castelhano e dos demais dados referentes à região de Venâncio Aires, foram compiladas diferentes bases cartográficas (Secretaria do Ambiente e Desenvolvimento Sustentável do Estado do Rio Grande do Sul - SEMA/RS, Diretoria do Serviço Geográfico DSG e Google Earth) e também foram geoprocessados dados altimétricos STRM (Shuttle Radar Topography Mission) utilizando o software livre Qgis, versão 3.1. Acerca da qualidade dos dados disponibilizados, destaca-se a Base Cartográfica da SEMA/RS [13], na escala 1:25.000, contendo drenagens, uso do solo e outras informações, dados estes em resolução superior às tradicionais cartas do exército (BDGEx) apresentadas em escala
1:50.000. Os dados STRM [14], recentemente disponibilizados com resolução de pixel de 30 metros, permitem uma análise mais precisa do que a feita à época por Collischonn [2], sobre dados STRM com pixel de 90 metros de resolução. Para o processamento e tratamento de imagens, foi utilizada metodologia análoga àquela apresentada por Elesbon et al. [15].

O Arroio apresenta um percurso de mais de $90 \mathrm{~km}$ de sua origem à sua foz e uma variação de altitude de mais de 600 metros (Figura 3). Na Figura 4, vê-se a declividade da bacia, que varia de 70 graus a 0 grau de inclinação. É possível observar que a bacia apresenta considerável transição de declividade entre seu alto curso (região serrana) e seu médio e baixo curso. 

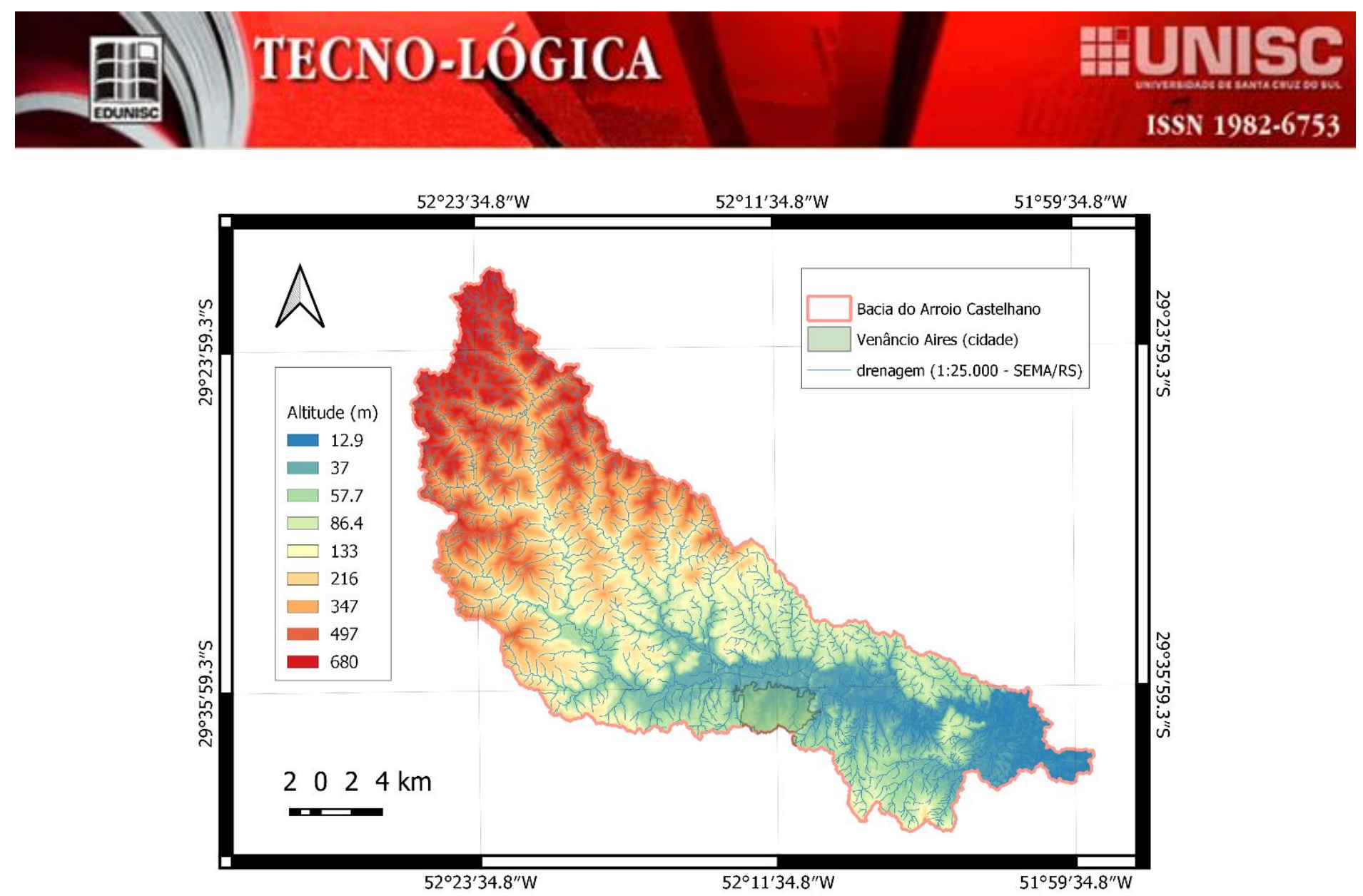

Figura 3 -Variação da altitude da Bacia do Arroio Castelhano (Composição STRM - 30m)

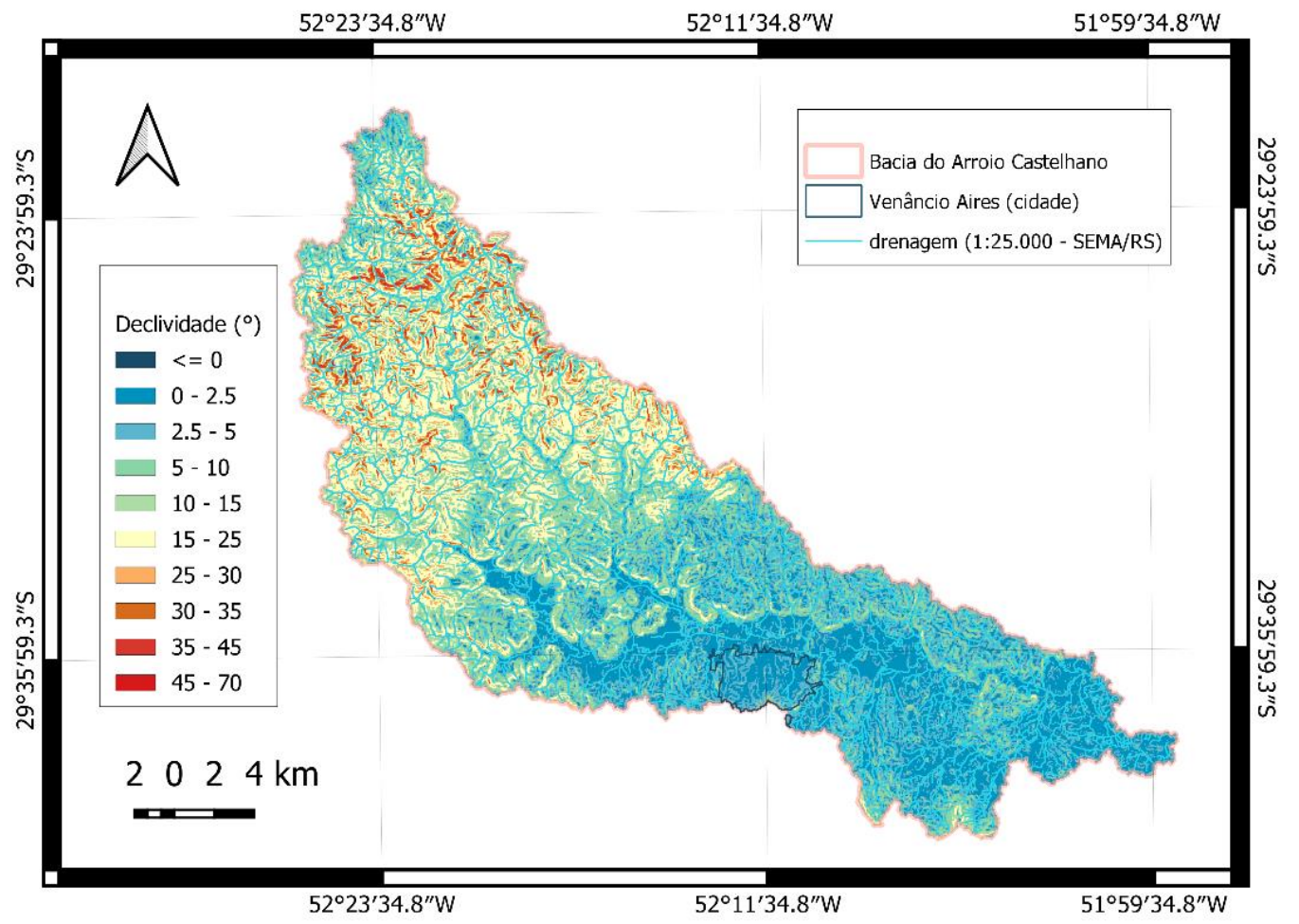

Figura 4 -Variação da declividade da Bacia do Arroio Castelhano (Composição STRM - 30m e Base SEMA/RS)

TECNO-LÓGICA, Santa Cruz do Sul, v. 24, n. 2, p. 148-159, jul./dez. 2020 
Na Figura 5, apresenta-se o perfil longitudinal do Arroio Castelhano. Collischonn [2] aponta o alto curso do arroio como sendo o trecho prévio à localidade de Monte Alverne (distrito do município de Santa Cruz do Sul/RS), o médio curso entre Monte Alverne e zona urbana de Venâncio Aires e o baixo curso desta até a foz, desaguando no Rio Taquari.

Do alto ao médio curso, existe considerável variação de declividade, tendo o alto curso maior declividade que o médio e baixo curso. Dos princípios da hidráulica, temos que a declividade, também chamada nesse caso de gradiente hidráulico (i), sendo a relação entre variação de altura e de distância (h/L), é diretamente proporcional à vazão $(\mathrm{Q})$ de um escoamento e inversamente proporcional à área (A) transversal do escoamento (Equação 1).

$\mathrm{Q}=\mathrm{A} * \mathrm{i}$

(Equação 1)
Tal variação de declividadejustifica, assim, a tendência a extravasamentos no curso médio e, principalmente, no curso baixo (pós-zona urbana de Venâncio Aires), ou seja, as ocorrências de inundações observadas.

Mesmo em um cenário sem contribuições de afluentes e com perdas de vazão (infiltrações, evaporação e aduções, entre outras), o decréscimo de (i) requererá acréscimo da área (A) para manutenção da vazão do curso d'água. Na realidade, há diversas entradas de vazão ao longo do percurso devido a contribuições dos afluentes e das drenagens, sendo expressiva a contribuição do Arroio Grande, pouco antes da zona urbana, e da própria drenagem urbana. Tem-se, então, na zona urbana um cenário composto pelo acréscimo de vazão e decréscimo da declividade, consolidando a diminuição da velocidade do fluxo d'água e o aumento da área alagada.

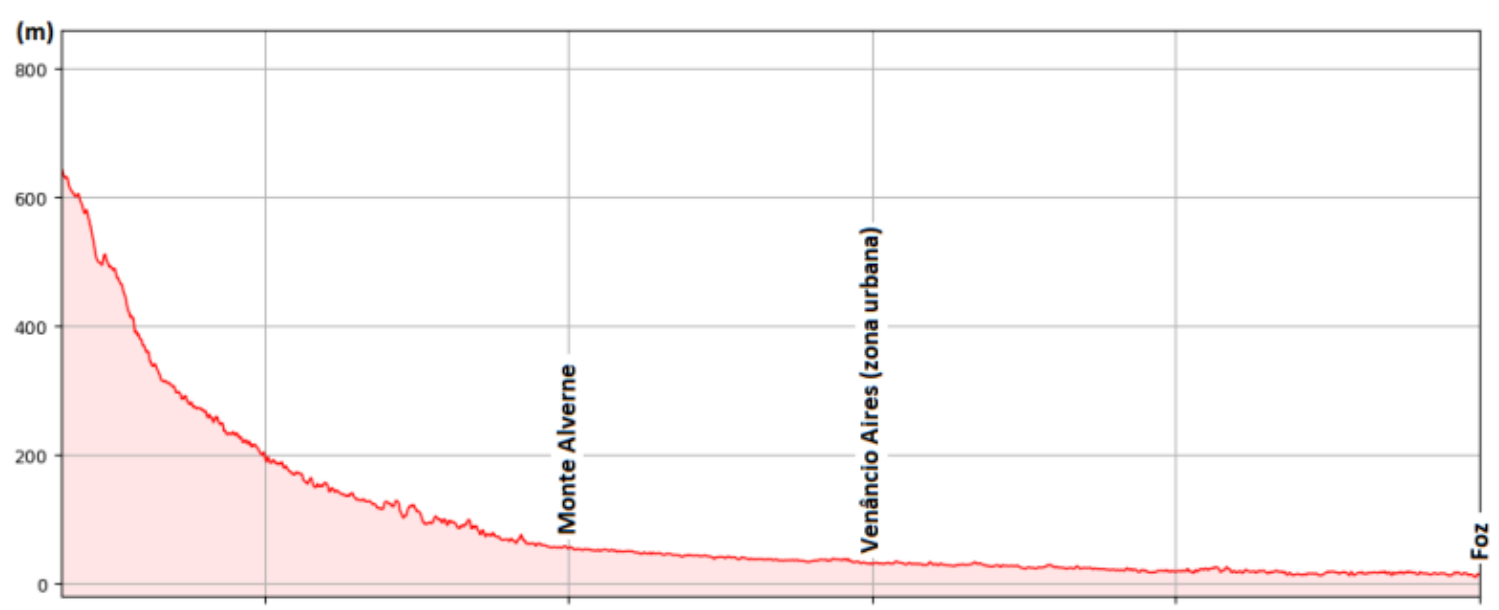

Figura 5 - Perfil longitudinal do Arroio Castelhano até sua Foz.

\subsection{Morfologia da Bacia}

A bacia apresenta forma próxima à elíptica, com subbacias (bacias dos principais afluentes) alongadas, o que faz com que uma chuva distribuída em toda a bacia gere vazões que, ao se somar ao curso principal, causem inundações.

Considerando a área e o perímetro da bacia $\left(578,07 \mathrm{~km}^{2}\right.$ e $225,44 \mathrm{~km}$, respectivamente), chegamos a um Índice de Circularidade (Ic) de 0,14 e a um Coeficiente de Compacidade (Kc) de 0,74. Tais valores colaboram para a interpretação de uma bacia próxima à forma retangular. Assis e Bayer [16] destacam que Ic inferiores a 0,51 correspondem a bacias com maior capacidade de escoamento superficial em comparação a bacias com Ic superior a 0,51 .
Com um comprimento axial estimado de 59,41 km, chega-se a um Fator Forma (Kf) de 0,16. Segundo Collischonn [2], bacias nessas condições não tendem a apresentar enchentes em sua foz. Outra característica a se ressaltar quanto à forma de bacia (alongada) é que estas não tendem a apresentar picos de vazão.

Ao analisarmos a bacia intermediária, onde a zona urbana está situada, considerando as contribuições do percurso do arroio em zona urbana, temos uma bacia com Ic e $\mathrm{Kf}$ mais elevados em comparação ao todo da bacia.

Com 1.296,00 km de drenagens (soma dos comprimentos das drenagens da bacia), tendo como base as drenagens indicadas na base cartográfica da SEMA/RS, a bacia do arroio apresenta 


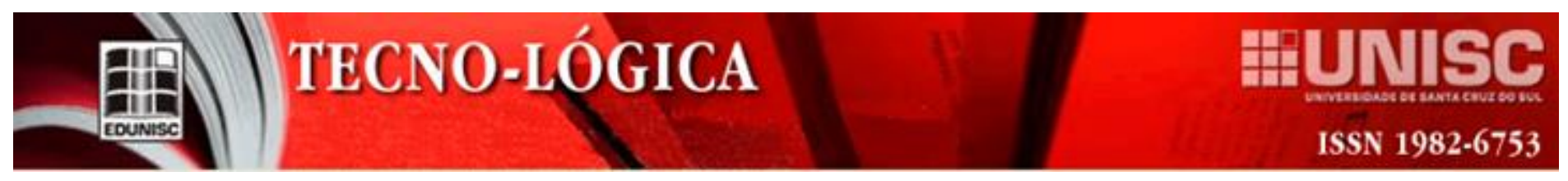

uma Densidade de Drenagem (Dd) de 2,24 [km/ $\left.\mathrm{km}{ }^{2}\right]$, podendo ser classificada como uma bacia bem drenada, segundo Villela e Mattos [17].

As equações para os parâmetros morfológicos apresentados podem ser vistas em estudos como os de Ferreira et al. [18], entre outros da bibliografia específica ao tema.

\subsection{Geologiada Bacia}

O município de Venâncio Aires encontra-se em uma transição desde depósitos aluvionares, ao sudeste, até derrames basálticos da Serra Geral, na região noroeste. A Bacia do Arroio Castelhano apresenta o mesmo dinamismo, com variedade de feições geológicas, abrangendo desde arenitos das Formações Rosário do Sul e Botucatu até rochas basálticas da Formação Serra Geral (Figura 6), seguindo essa ordem estratigráfica. Identificada como Rosário do Sul em mapeamento apresentado pela CPRM em escala 1:250.000, tal estrato da região sul da bacia corresponde a estratos da Formação Santa Maria, depósito sedimentar de origem fluvial. Quanto à ocorrência da Formação Botucatu, embora tenha extensa demarcação na cartografia disponibilizada pela Secretaria de Meio Ambiente (SEMA) do Estado do Rio Grande do Sul, em escala 1:250.000, esta é identificada em porções isoladas, conforme destaca Collischonn [2].

A Formação Serra Geral apresenta intercalações de derrames de rochas efusivas, sendo que na cabeceira da bacia se identifica a ocorrência de rochas ácidas, a Fácies Caxias, constituída de riolitos, dacitos e riodacitos. Em ambas as variantes da Formação Serra Geral na bacia, é comum identificar a intercalação com lentes de arenito. Outra característica marcante, relevante no contexto hidrológico, é a ocorrência de falhas e, principalmente, de fraturas, as quais são responsáveis pela característica hidrogeológica de sua respectiva porção da bacia. Tal recurso hidrogeológico é responsável pela recarga da água superficial em períodos de maior estiagem, tornando raras as ocorrências de baixa disponibilidade hídrica do Arroio Castelhano. Quanto às áreas de menor declividade e próximas à área urbana, há ocorrência de depósitos aluvionares holocênicos, constituídos de siltes, argilas e areias (em menor quantidade), típicos de planícies de inundação.

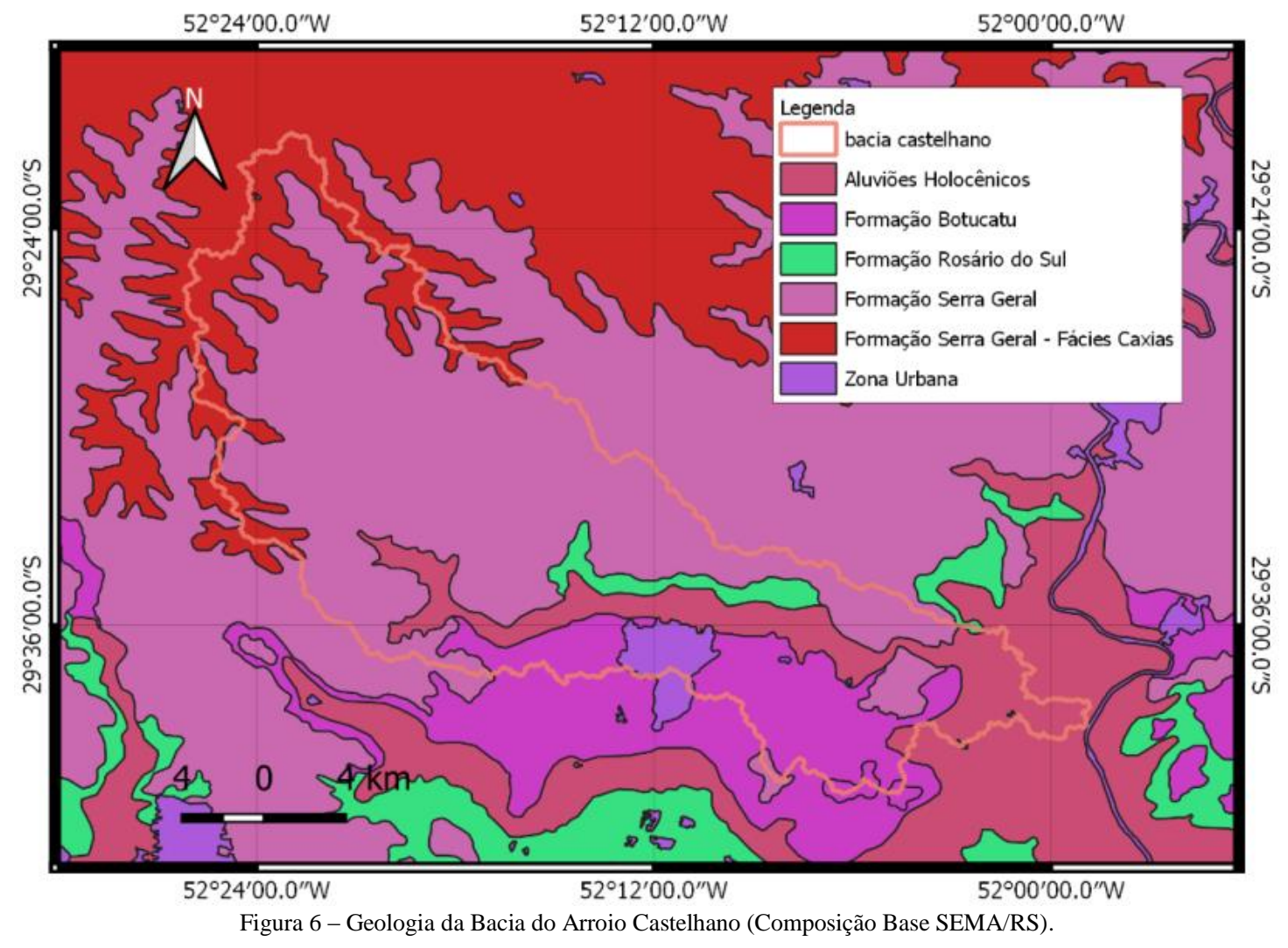

TECNO-LÓGICA, Santa Cruz do Sul, v. 24, n. 2, p. 148-159, jul./dez. 2020 


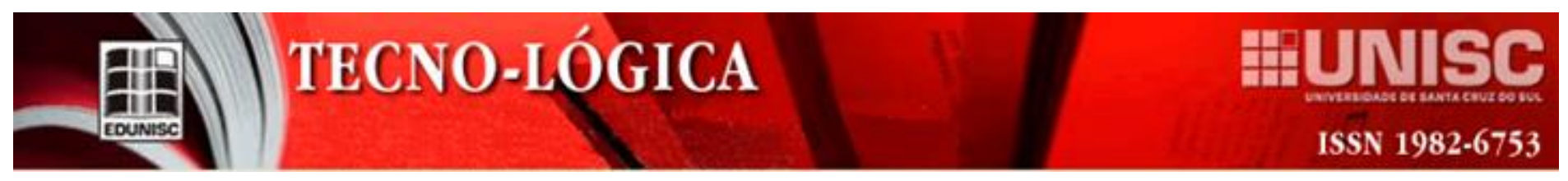

\subsection{Geomorfologia da Bacia}

Devido ao fato de uma significativa porção do município e, consequentemente, da Bacia do Castelhano encontrar-se nas bordas da Formação Serra Geral, ocorre uma variação abrupta de declividade das planícies suaves (baixa declividade) dos depósitos aluvionares e das formações sedimentares (Botucatu e Rosário do Sul) ao relevo acidentado e à alta declividade dos derrames basálticos da Formação Serra Geral. Na Figura 7, observa-se a geomorfologia presente na Bacia do Arroio Castelhano. Venâncio Aires encontra-se em duas regiões geomorfológicas, a Depressão Central Gaúcha (composta pelas unidades Depressão do Rio Jacuí e Planícies AlúvioColuvionares) e o Planalto das Araucárias (representado por três unidades: Patamares da Serra Geral, Serra Geral e Planalto dos Campos Gerais).

Sobre a caracterização de solos, destaca-se a baixa permeabilidade (solos mal drenados) na zona urbana e as áreas próximas, coincidentes às áreas de menor declividade; tais ocorrências são naturalmente responsáveis por enxurradas [19]. Os tipos de solo são intricadamente ligados à geomorfologia.

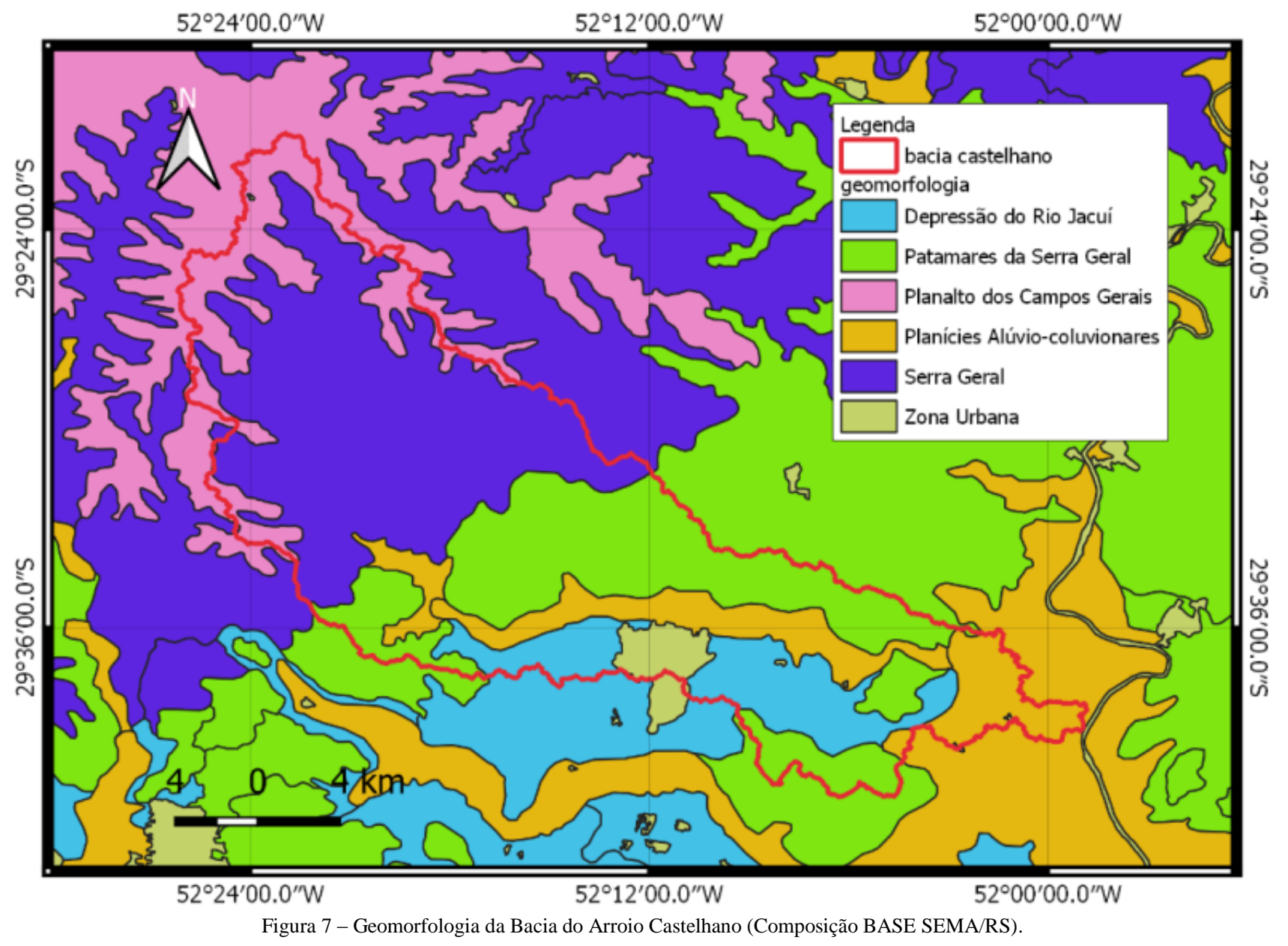

\section{Gestão Urbana e Prevenção/Mitigação de Inundações}

É consenso que a gestão urbana desempenha papel fundamental na prevenção e minimização de inundações. Na cidade de Venâncio Aires, há cenários qualificados como de alto risco, tanto para ocorrências de danos devido a inundações quanto para a qualidade da oferta hídrica. Na zona urbana, em especial, esse recurso é responsável pelo suprimento de água para a maior parte da população, sendo motivo de grande preocupação. 
No caso da Bacia do Arroio Castelhano, embora existam ocupações irregulares que são atingidas pelas inundações da várzea do arroio, destacam-se como áreas mais impactadas as urbanizadas, onde foram executados loteamentos sobre os quais se estabeleceram residências, comércios e indústrias. Essas áreas estão entre as mais urbanizadas da cidade, pavimentadas, com disponibilidade de recursos e bem assistidas pelo poder público. Justamente essa ocupação com residências de médio padrão, comércios e indústrias torna tão importante para a cidade a gestão de inundações, dados os potenciais prejuízos econômicos e sociais.

Tucci [5], ao abordar as possibilidades de gerenciamento de riscos de inundações, é enfático ao afirmar que, na maioria dos casos, intervenções estruturais (barragens e demais estruturas de contenção e retenção) são opções mais custosas que as não estruturais (regulação de uso do solo, seguros e outros). $\mathrm{O}$ autor também ressalta que técnicas preditivas, como, por exemplo, cálculo da frequência de chuvas, sua intensidade e elaboração de hidrograma do curso d'água, são classificadas como medidas não estruturais no controle de inundações e danos associados. Destaca-se que, mesmo para a adoção (de forma adequada) de medidas estruturais, essas ferramentas (hidrogramas, frequência e intensidade de chuvas) são fundamentais, uma vez que oferecem subsídios para o projeto e o dimensionamento de estruturas importantes, como barragens, bacias de retenção e contenção, entre outras.

No caso do Arroio Castelhano, destaca-se como ação estrutural já executada a retificação de trecho do arroio próximo à zona urbana [2], medida tomada à época com o intuito de minimizar inundações. A falta de manutenção (desassoreamento do leito) e de barramento do fluxo para o leito antigo, somada à falta de continuidade da retificação, contribuiu para a ineficiência da intervenção realizada. Da divisão da vazão do arroio (mesmo que parcialmente) em dois (leito antigo e novo), tem-se naturalmente uma vazão menor em ambos do que na situação de fluxo direcionada em apenas um leito; assim, observa-se uma menor velocidade de escoamento, fatorinfluente para inundações e deposição de sedimentos (assoreamento, que contribui para extravasamentos de leito).

Canholi [20], além de proceder a uma compilação de medidas estruturais, pondera que a combinação de medidas é aconselhável em diversas situações. O autor apresenta medidas mitigatórias alternativas, como (i) estruturas de biorretenção, (ii) poços secos, (iii) trincheiras de infiltração, (iv) bacias de infiltração e bacias de retenção de pequeno volume, (v) telhados verdes, (vi) alagados construídos e (vi) pavimentos permeáveis, entre outros.
Com referência às medidas não estruturais, destaca-se o próprio plano diretor do município, que visa regular o uso do solo e dispõe sobre área de interesse ambiental, a qual corresponde à várzea do Arroio Castelhano. Outra medida encontra-se no Código de Obras Municipal, que prevê áreas permeáveis mínimas e medidas de amortização de vazões para áreas impermeabilizadas superiores a $500 \mathrm{~m}^{2}$. Entretanto, em suas conclusões, Collischonn [2] já destacava a pouca efetividade de medidas de gestão das áreas de risco, que não vinham afastando a ocupação dessas áreas. Cabe ainda salientaras alterações do plano diretor da cidade de Venâncio Aires, que viabilizaram ocupações nas zonas classificadas como de risco de inundação e como área de preservação ambiental, conforme se observa nos trabalhos de Lücke [9] e Vogt [21], havendo uma clara expansão da zona urbana do município em direção à várzea do Arroio Castelhano.

\section{Considerações Finais}

Com relação às características geomorfológicas da bacia, somada à geologia e à cobertura do solo (variações de vegetação), tem-se naturalmente uma bacia com tendências a grande amplitude de vazão e a extravasamentos no seu curso médio e baixo. As variações de declividade, das coberturas de solo e principalmente dos aspectos morfológicos da bacia mostram ser esperadas as inundações ou saídas do leito regular do arroio. Identifica-se a área que vai desde pouco antes do início da zona urbana de Venâncio Aires até a foz do Arroio Castelhano como propensa a inundações.

No caso das inundações na zona urbana do Arroio Castelhano, acontecem agravamentos de situação devido a fatores amplamente conhecidos: falta de planejamento do uso do solo e urbanização inadequada. Esses dois fatores entrelaçam-se, já que se observa tanto a ocupação da conhecida várzea de inundação do arroio, vide histórico de expansão urbana em direção a esta, quanto à impermeabilização da mesma com pavimentações e edificações, bem como a ausência de adoção de medidas de regularização da drenagem urbana. Quanto ao uso do solo, ao considerarmos a porção norte da bacia intermediária (área rural), acima da zona urbana, vemos uma maior alteração da vegetação nativa para atividades agrossilvipastoris, contribuindo para um maior escoamento superficial e carregamento de sedimentos.

Embora haja, na porção montante da Bacia do Arroio Castelhano, uma retomada da vegetação nativa, cooperando para a atenuação de ondas de cheias na porção de declividade mais atenuada (a jusante e próximo à zona urbana), região que naturalmente representa maior retenção de águas pluviais (escoamento lento) segundo Tucci [6], percebe-se menor 
incidência de vegetação natural e maior área impermeabilizada ou de baixa permeabilidade.

Pode-se concluir que os fatores passíveis de atuação na Bacia do Arroio Castelhano, encontram-se próximos à zona urbana. Dentre as opções de atuação do poder público, citam-se ações mais factíveis e de menor custo, como a regulação do uso do solo. Collischonn [2] já apontava em seu estudo o zoneamento urbano, através do plano diretor, como problemático. Desde 2009, ao contrário de uma regulação de uso do solo e de medidas que visassem à minimização do impacto da drenagem pluvial urbana na Bacia, ocorreu avanço da área urbana em direção à área de várzea e obras de urbanização nas áreas problemáticas (de risco de inundação e de escoamento lento). Houve, portanto, um manejo amplamente inadequado da situação.

Quanto a medidas estruturais, um primeiro passo, que demandaria baixo investimento do poder público, é a adoção de uma política de impacto zero sobre a drenagem pluvial, exigindo-se que todo empreendimento que venha a modificar as condições de escoamento, alterando taxas de infiltração, adote medidas mitigatórias ou compensatórias aos seus impactos. Rose [22] pondera que, para efeitos de ações dessa natureza (difusa) apresentarem resultados visíveis, executados coletivamente, é necessária ainda a atuação sobre os passivos. No caso em questão, consiste em cobrar medidas mitigatórias de empreendimentos e edificações já existentes.

Outra medida que poderia ser adotada sem extensivo custo seria a concepção de uma política de planejamento urbano voltada à gestão da drenagem urbana, privilegiando-se projetos de calçadas e espaços públicos de maior permeabilidade e retenção de águas pluviais.

Por parte do meio rural (porção da Bacia ao norte da zona urbana) poderiam ser incentivadas práticas e manejos que recuperassem a vegetação nativa, minimamente o previsto como Área de Preservação Permanente (APP) de cursos hídricos - 30 a 50 metros de cada margem do Arroio (a depender de sua largura) e principalmente de seus afluentes, medidas mínimas em meio urbano, mas flexibilizada em área rural, conforme Código Florestal [23]. Considerando queo Arroio Castelhano possui grande extensão com largura superior a 10 metros e a quase a totalidade de seus afluentes apresenta largura inferior a 10 metros.

Menos factível, dada a geomorfologia da Bacia e o posicionamento da zona urbana, seria a execução de uma barragem a montante para regulação do regime hídrico. Esta seria uma medida extrema, tornando-se praticamente inviável.
Observa-se, conforme os mapas de altitude e declividade (Figuras 2, 3 e 4), que a área a montante da zona urbana apresenta baixa variação desses indicadores, situações que $a$ priori resultariam em grande complexidade para uma solução estrutural. Nesse cenário, uma grande área seria impactada por barramento e diques.

Destaca-se ainda que a confluência com o Arroio Grande próxima à zona urbana (Figura 2), que representa considerável aporte de vazão (dada a área de sua sub-bacia), torna pouco efetiva a execução de barramento em porção mais a montante do Arroio Castelhano. Contudo, deve-se levar em consideração a ausência de estudos hidrológicos básicos para estudos de viabilidade e tomadas de decisão quanto a medidas estruturais da natureza de barragens, diques e bacias de retenção ou acumulação.

\subsection{Potenciais Estudos}

Menos factível, dada a geomorfologia da Bacia e o posicionamento da zona urbana, seria a execução de uma barragem a montante para regulação do regime hídrico. Esta seria uma medida extrema, tornando-se praticamente inviável. Observa-se, conforme os mapas de altitude e declividade (Figuras 2, 3 e 4), que a área a montante da zona urbana apresenta baixa variação desses indicadores, situações que $a$ priori resultariam em grande complexidade para uma solução estrutural. Nesse cenário, uma grande área seria impactada por barramento e diques.

Destaca-se ainda que a confluência com o Arroio Grande próxima à zona urbana (Figura 2), que representa considerável aporte de vazão (dada a área de sua sub-bacia), torna pouco efetiva a execução de barramento em porção mais a montante do Arroio Castelhano. Contudo, deve-se levar em consideração a ausência de estudos hidrológicos básicos para estudos de viabilidade e tomadas de decisão quanto a medidas estruturais da natureza de barragens, diques e bacias de retenção ou acumulação.

\section{Agradecimentos}

O Autor principal agradece aos ex-colegas da Secretaria de Meio Ambiente do Município de Venâncio Aires, em especial a Eng. Ftal. Clarissa Gomes pelas ótimas observações quanto este trabalho. 


\section{CASTELHANO STREAM BASIN \\ CHARACTERIZATION: WATER AVAILABILITY, FLOOD RISKS AND INTERACTION WITH THE CITY OF VENÂNCIO AIRES / RS}

\begin{abstract}
This work aims to characterize the Castelhano stream basin and its relationship with the municipality of Venâncio Aires/RS, Brazil. The authors describe how the geomorphological nature of this basin and the use of land in rural and urban areas have an influence on the quality of the stream's water as well as on its flow rate and flooding events. The analysis of morphological indices and geomorphology shows that the stream basin has flooding tendencies in its middle stretch. The authors concluded that, due to geomorphology and land use, the area with the greatest possibility of intervention in terms of flooding episodes is located in the urban area of the municipality and in the rural areas close to it, which are areas of low declivity.
\end{abstract}

Keywords: Castelhano Stream. Hydrographic Basin. Venâncio Aires/RS.

\section{Referências}

[1] MARIMON, Maria Paula Casagrande. O Flúor nas Águas Subterrâneas da Formação Santa Maria, na Região de Santa Cruz do Sul e Venâncio Aires, RS, Brasil. Tese de Doutorado. Universidade Federal do Rio Grande do Sul. 2006.

[2] COLLISCHONN, Erika. Inundações em Venâncio Aires/RS: Interações entre as dinâmicas natural e social na formação de riscos socioambientais urbanos. 2009. 327 f. Tese (Programa de Pós-Graduação em Geografia Doutorado) - Universidade Federal de Santa Catarina, Florianópolis. 2009.

[3] INSTITUTO BRASILEIRO DE GEOGRAFIA E ESTATÍSTICA (IBGE). Cidades@. Disponível em: <https://cidades.ibge.gov.br/brasil/rs/venancioaires/panorama>. Acesso em outubro de 2019.

[4] OLIVEIRA, Mauro André de. Modelagem dinâmica espacial das classes de uso e cobertura da terra de Venâncio Aires/RS. 2015. 80 f. Trabalho de Conclusão de Curso (Curso de Engenharia Ambiental) - Universidade do Vale do Taquari, Lajeado. 2015.

[5] TUCCI, C. E. M. Água no meio urbano. In: REBOUÇAS, A.; BRAGA, B.; TUNDISI, J. G. Uso e conservação. 2. ed. São Paulo: Academia Brasileira de Ciências, Instituto de Estudos Avançados, USP, 2002. p. 473-506.

[6] TUCCI, Carlos EM. Inundações urbanas. Porto Alegre: ABRH/RHAMA, v. $11,2007$.

[7] MACIEL, Filho. Carlos L.; NUMMER, Andréa V. Introdução à Geologia de Engenharia. Santa Maria: EditoraUFSM, 2014.

[8] WESCHENFELDER, Wilson Junior; AREND, Silvio Cezar. A Ocupação do Solo em Área Preservação Permanente: O Avanço Sobre a Planície de Inundação do Arroio Castelhano na Área Urbana de Venâncio Aires, RS. In.: Anais do II Congresso Brasileiro de Gestão Ambiental. Londrina, PR. 2011.
[9] LÜCKE, Sabrina Assmann. Planejamento e cidades: plano diretor em Venâncio Aires/RS. 2013. 151 f. Dissertação (Programa de Pós-Graduação em Ambiente e Desenvolvimento - Mestrado) - Universidade do Vale do Taquari, Lajeado. 2013.

[10] BÖHM, Juliara Stahl et al. Response of epilithic diatom communities to downstream nutrient increases in Castelhano Stream, Venâncio Aires City, RS, Brazil. Journal of Environmental Protection, v. 4, n. 11, p. 20-26, 2013.

[11] MACHADO, NeliGalarce; LÜCKE, Sabrina Assmann. Estatuto da cidade e Plano Diretor em Venâncio Aires/RS. Revista Brasileira de Gestão e Desenvolvimento Regional, v. 10, n. 4,p. 152-170, set./dez. 2014.

[12] MARCUZZO, Francisco Fernando Noronha et al. Espacialização mensal e anual da chuva nos municípios de Santa Cruz do Sul, Venâncio Aires, Vera Cruz e Passo do Sobrado no Rio Grande do Sul. Anais do XXII Simpósio Brasileiro de Recursos Hídricos.Florianópolis/SC, 2017.

[13] SECRETARIA DO AMBIENTE E DESENVOLVIMENTO SUSTENTÁVEL (SEMA-RS). Base Cartográfica do Rio Grande do Sul. Porto Alegre, 2018. Disponível em: <https://www.sema.rs.gov.br/cartografia〉. Acesso em outubro de 2019.

[14] INSTITUTO NACIONAL DE PESQUISAS ESPACIAIS (INPE). Topodata - banco de dados geomorfométricos locais do Brasil. 2011. Disponível em: <http://www.dpi.inpe.br/topodata/data/grd/>. Acesso em outubro de 2019

[15] ELESBON, Abrahão Alexandre Alden et al. Uso de dados SRTM e plataforma SIG na caracterização morfométrica da bacia hidrográfica do Braço Norte do Rio São Mateus-Brasil. Rem: Revista Escola de Minas, v. 64, n. 3, p. 281-288, 2011.

[16] ASSIS, Pâmela Camila; BAYER, Maximiliano. Análise dos parâmetros morfométricos da bacia do Rio Claro-sub bacia do Rio Araguaia-Goiás. Os Desafios da Geografia Física na Fronteira do Conhecimento, UNICAMP, v. 1, p. 926-931, 2017.

[17] VILLELA, Swami Marcondes; MATTOS, Arthur. Hidrologia aplicada. Hidrologia aplicada. São Paulo. McGraw-Hill, 1975.

[18] FERREIRA, José Henrique Cruz et al. Morfometria da microbacia do Córrego Feijoal-Ubaporanga/MG. Revista de Ciências, v. 8, n. 2,p. 74-86, 2017.

[19] FENDRICH, Roberto et al. Drenagem e controle da erosão urbana. Curitiba Editora Universitária Champagnat, 1984.

[20] CANHOLI, Julio Fracarolli. Medidas de controle in situ do escoamento superficial em áreas urbanas: análise de aspectos técnicos e legais. 2013. $184 \mathrm{f}$. Dissertação (Programa de Pós-Graduação em Engenheria Hidráulica e Sanitária - Mestrado) - Universidade de São Paulo, São Paulo. 2013.

[21] VOGT, Olgário Paulo. Abrindo o Baú de Memórias: O Museu de Venâncio Aires conta a história do município. Santa Cruz do Sul: EDUNISC, 2004.

[22] ROSE, Jonathan F.P. A Cidade em Harmonia: O que a Ciência Moderna, Civilizações Antigas e a Natureza nos Ensinam Sobre o Futuro da Vida Urbana. Porto Alegre: Bookman, 2019.

[23] BRASIL. Lei $n^{\circ} 12.651$, de 25 de maio de 2012. Dispõe sobre a proteção da vegetação nativa e dá outras providências. Diário Oficial da União, 2012. 